\section{hommes}

\section{Hommes \& migrations}

Revue française de référence sur les dynamiques

migratoires

$1324 \mid 2019$

Religion et discrimination

\title{
Des guerres invisibles
}

\section{Marianne Amar}

\section{OpenEdition \\ Journals}

\section{Édition électronique}

URL : https://journals.openedition.org/hommesmigrations/8820

DOI : $10.4000 /$ hommesmigrations. 8820

ISSN : 2262-3353

\section{Éditeur}

Musée national de l'histoire de l'immigration

\section{Édition imprimée}

Date de publication : 1 janvier 2019

Pagination : 146-147

ISBN : 978-2-919040-44-5

ISSN : $1142-852 X$

\section{Référence électronique}

Marianne Amar, «Des guerres invisibles », Hommes \& migrations [En ligne], 1324 | 2019, mis en ligne le 01 janvier 2019, consulté le 06 janvier 2022. URL : http://journals.openedition.org/ hommesmigrations/8820; DOI : https://doi.org/10.4000/hommesmigrations.8820 


\section{DES GUERRES INVISIBLES}

Entretien avec Benjamin Stora, historien, président du Conseil d'orientation du Musée national de l'histoire de l'immigration, réalisé par Marianne Amar.

Hommes \& Migrations: Les deux guerres d'Algérie - guerre d'indépendance et guerre civile des années 1990 - apparaissent l'une et l'autre marquées par l'invisibilité. Selon quel processus s'est construite cette impossibilité à montrer les conflits et leurs acteurs? Est-ce qu'il y a entre les deux conflits des traits communs? Des ruptures?

Benjamin Stora: D'une guerre à l'autre, la censure des images construite par le politique tire, à l'évidence, un fil rouge. Mais il faudrait nuancer entre les formes d'images, d'une part, et entre les guerres, d'autre part. Pendant la guerre d'indépendance, la censure frappe au premier chef les images de fiction, moins les photographies, si l'on se réfère par exemple à celles que publie Paris Match. La seconde guerre d'Algérie se déroule, elle, entièrement à huis clos. C'est pour cela que je l'ai nommée « la guerre invisible ${ }^{\mathbf{1 0}}$ ». Les journalistes étrangers n'ont pas accès au territoire de la guerre, faute de visa pour entrer en Algérie. Par ailleurs, ce sont l'une et l'autre des guerres sans front, donc sans lieu où saisir les combats entre deux ennemis, sans lieu où mettre en scène l'affrontement.

Tout ne se ressemble pas néanmoins entre les deux guerres. La première, parce qu'il s'agit d'une guerre d'indépendance, rend lisible la ligne de partage entre l'étranger et le national, et donc les enjeux de la guerre. En revanche, le conflit des années 1990 trace une ligne de fracture au sein même de la société algérienne: le pays se trouve plongé dans une guerre civile dont on peine à comprendre la signification.

10. Benjamin Stora, La guerre invisible. Algérie, années 90, Paris, Presses de Sciences Po, 2001. 
L'invisibilité tient aussi aux combattants, qui choisissent de rester invisibles: dans ces guerres sans front, ne pas être vu, se dissimuler fait partie de l'arsenal guerrier. Enfin, je voudrais insister sur un point: l'invisibilité renvoie aussi à leur condition de dominés. Les combattants, issus d'une société rurale, n'ont accès ni à l'image, ni à la parole, ni aux outils de représentation. Bien sûr, ceux des années 1990 viennent d'une société qui s'est fortement urbanisée en trente ou quarante ans, et d'une population mieux formée, mais le problème demeure largement.

Enfin, il faut se souvenir de l'extraordinaire violence de ces deux conflits. Dans l'absence d'images, on ne peut laisser de côté les formes d'auto-censure, la sensibilité et l'éthique des auteurs qui ne peuvent tout simplement pas montrer l'événement, passé un certain degré de barbarie.

\section{H\&M: Est-ce que cette invisibilité des guerres pèse sur la visibilité des migrants algériens dans l'espace public de la métropole?}

B. S.: Je pense qu'il faut insister sur un point: sur le sol métropolitain, ils ne sont pas des «dominés» comme les autres, parce qu'ils ont un statut spécial. Ils ne sont ni français, ni étrangers - d'ailleurs, ils ne sont pas recensés comme tels -, ni sujets coloniaux. Cette absence de nomination renvoie à l'incapacité de nommer la guerre et les situations qu'elle génère, mais aussi aux changements de nom patronymique imposés par l'administration coloniale. Elle a imposé une vaste opération d'état civil dans les années 1880, qui a coupé les Algériens de leur nom traditionnel, et donc de leur généalogie. De surcroît, certains Algériens se sont retrouvés durablement «sans nom patronymique», et d'autres avec des noms qui n'évoquaient rien ou étaient chargés de contenus sémantiques infamants et donc impossibles à prononcer.

Si l'on revient sur la situation des migrants, à la confusion sur les statuts que j'ai évoquée, s'ajoutait le refus des Français de les nommer "Algériens». D'une certaine manière, on peut considérer que seul l'engagement politique leur redonnait une base identitaire et une dignité. Plus généralement, pour les migrants algériens, il faut relier les enjeux d'invisibilité à l'entreprise de destruction de la culture algérienne menée par le colonisateur. Et comprendre, par ce biais, l'importance d'afficher une identité dans l'espace public, notamment par le drapeau.

\section{H\&M: Comment écrire cette histoire malgré tout, en dépit de l'absence d'images ou de traces? Quels détours emprunter pour la rendre visible, en dépit de l'invisibilité?}

B. S.: Paradoxalement, par la fiction, la littérature qui parvenait à échapper à l'interdit posé par la censure. C'est ce que j'ai essayé de montrer dans mon ouvrage de 2005, Le livre, mémoire de l'Histoire"1". Du côté des images, par la peinture, la création artistique, le cinéma... Mais aussi, plus tard, par le témoignage, en essayant de faire parler les «silencieux». Car les invisibles sont aussi des sans-voix, ou plutôt des voix inaudibles.

11. Benjamin Stora, Le livre, mémoire de l'Histoire. Réflexions sur le livre et la guerre d'Algérie, Paris, Le préau des collines, 2005. 